\title{
Gender Perspective in Political Campaigns
}

\author{
Ni Ketut Sri Rahayuni ${ }^{1}$, I Gusti Ngurah Parthama ${ }^{2}$, I Komang Sumaryana Putra ${ }^{3}$
}

\author{
Faculty of Arts-Udayana University \\ Denpasar \\ Faculty of Arts-Udayana University \\ Denpasar \\ Faculty of Arts-Udayana University \\ Denpasar
}

\begin{abstract}
This paper aims to describe political discourse that has a link with gender on outdoor media campaigns. The media of outdoor campaigns is the most effective public space to be able to convey various matters relating to a candidate for both a leader and a member of parliament especially if it is associated with gender which is still a major problem in Indonesia. Gender in Indonesian politics is still unbalanced considering not yet optimal and balance the contribution between men and women in politics world. It was a major concern on outdoor media campaign of a number of female candidates in the 2014 legislative election. Sources of data from this paper are taken from areas - Badung, Jembrana, Klungkung, and Denpasar. Method of data collection was done by way of recording by photographing media outdoor campaign containing information related to gender. Furthermore qualitative descriptive method became an option to describe the data - research data related to discourse theory and gender theory in the use of language. Result of the analysis showed that gender is one of the election discourses of the candidates of the people's representatives, especially the women to get the vote and sympathy. For that reason, the projection of the use of gender terms, equality of rights, and struggle with men is the primary choice to demonstrate the struggle for gender equality. Variations of use are also seen but by maintaining the gender side of women as parties who are fighting for their rights.
\end{abstract}

Index Terms - gender, campaign, politic, discourse.

\section{INTRODUCTION}

In general, the excellence of oral discourse is more about the promptness of information delivery. It relates to the direct interaction of the speaker. This is the same as speakers who involved in the conversation, speakers who use the telephone, as well as other oral interaction models. Direct delivery is of course very effective and efficient because communication can achieve the purpose of each speaker so it can obtain the agreement in a conversation. While the lack of oral discourse because there are no form of notes and recordings of a conversation that occurs because the oral discourse that occurs is usually an unplanned interaction between speakers. Meanwhile, written discourse has more advantages in information storage. In this case the written form allows a person to have a recording or record of the information it conveys. So it is possible that speakers involved in written discourse to review the information that has been submitted. In terms of shortage, written discourse, of course, follows strict rules of writing. So natural errors like those commonly found in oral discourse are hard to find. That is, the nature of written discourse is usually lower than oral discourse.

From various written discourse, political discourse becomes the most interesting thing to be analyzed. Political discourse is a discourse that arises in the realm or political field. In this case, politics is closely related to a situation in a community group in which they agree on a binding rule on the circumstances they are undergoing. Simply put, the 
politics that govern the society to abide by the rules, make rules, and matters relating to policies in society (political associations). In a political association it is possible that physical coercion is based on mutually agreed values and for the common good. So in general, the association was institutionalized and in its development emerged terms such as the government that provided values through the Constitution (UUD), the Act (UU), government regulations, and other official rules [1].

Through the value agreement, this research tries to analyze values in political discourse from the perspective of gender. Socially, gender has an understanding as a differentiator between men and women seen from roles and functions. Narwoko and Suyanto [1] reveal that gender is not determined by biological differences, but rather the position, function, and role of each. So in general, gender is actually a formation after birth that is developed and internalized by the people in their neighborhood.

Sulistyaningsih in her article entitled Bahasa Indonesia in the Political Propaganda Discourse of the 2009 Election Campaign is a very interesting in which describe languages processed in such a way as a medium for imaging, informing and inviting candidates. So with the choice of words - the appropriate words are believed to bring sympathy and become an option for the people. Sulistyaningsih further revealed that there are various things used to generate propaganda in the use of language in the media campaign. Diversity is like words with a positive inclination, the use of an academic degree, and the jargon of invitation for the electorate. Positive words used by candidates in the media campaign include honest, courageous, trustworthy, caring, professional, young, Islamic, experience, and effort. Positive vocabulary selection also adds value to legislative candidates considering the positive interpretation also emerged from the voters. In addition, the use of academic degree also raises the title or 'image' that the legislative candidate has adequate education qualification as the people's representative. So the use of an academic degree is also often raised on the media campaign.

In addition, Panggabean revealed that language is actually a form of power. Mastery of language is a mastery of power. Often the rulers use certain word choices that make their listeners unnerved. From that understanding can also be drawn the conclusion that the language in the media campaign actually has two functions. Both functions are functions to express something, but at the same time also trying to hide something. Although it is often said that the language in the media campaign is a language that is real, real, and connotative, but there are still other interpretations that arise from the readers.

Interpretation is also a serious concern for the novice voters. [2], notes that novice voters have certain characteristics in determining the choice of the candidates. Moreover, beginner voters are the first voters to use the choice. Surely they are potential voters if they are able to be influenced. Rozak put forward a few things that are almost similar to Sulistyaningsih related components on the media campaign of the candidates. Media campaigns of concern to Rozak's research are self-portraits of candidates in campaign media, costume options, academic degrees; campaign media color designs, jargon, and installation locations. For novice voters, the expression of legislative candidates is a major concern. Through the self-image of the candidates, it can be found the meaning of the expression of candidates. Smiling expression to clasp hands on the chest has its own meaning for novice voters. But interesting from [2], the use of candidates' photo on the media campaign actually has another interpretation. Beginner voters consider the candidates to show political narcissism through their photographs. Moreover, the photos on the media campaign installed in strategic locations. In general, photographs and costumes are still not a serious consideration for novice voters to convey their choice.

While the media color design and the jargon of legislative candidates become an important concern of beginner voters. Campaign media color design is usually tailored to the color of the candidate's party. For example, if the campaign media is red then it closely related to the Party of PDI Perjuangan. In addition, if interpreted normatively, the red citizen is identical with firmness and courage. While the jargon or word choice verbally from candidates is more to get attention. It's just that short, solid, and informative jargon is the consideration of the novice voter. The reason is that such jargon is easier to remember and sticks in the minds of the voters. Jargon with short, dense, and informative characteristics tends to have a combination of seven words. The choice of seven words is due to the seven-second time for the road users to see the jargon of the candidates. By jargon or verbal choice the word actually has certain intentions. Jargon means the purpose or power of a speech. So it is not solely to emphasize the speech only. For this reason, Searle in Leech [3] shares the meaning or power of a speech into five parts: representative or assertive, directive, expressive, commissive, and declarative. The more detailed divisions relate to the purpose or power of an illocutionist speech.

A representative or assertive speech act is a speech act that binds the speaker to the truth of what he says. For this reason, act representative or assertive speech is represented with words like; states, reports, shows, and mentions. Directive speech act is a speech act performed by a speaker with the intention that the listener to take action in his speech. These speech acts are usually represented with words such as; ask, beg, advise, and challenge. While expressive speech acts emphasize speech by the speaker as a form of evaluation of something and the form of evaluation is represented by words such as; praise, criticize, and complain. Meanwhile the commisive speech acts more emphasis on the implementation of what is in the speech of a speaker and it binds a speaker to be able to carry it out. 
Commissive speech acts are represented by words such as; threatening, promising, and swearing. The last act of speech is the act of declarative speech. Declarative speech acts are speech acts done by the speaker with the intent to create something new. Therefore, the words that are often used in this speech are among others; decide, cancel, and allow.

It should also be recognized that the intent or force of an illocution or perlocution speech may change based on the context in which the speech is performed. Context, the next determinant to find out is the purpose to be achieved. Parker [4] says that the context of the use of speech and the people involved in it greatly determines the purpose of an utterance. For example, if you say better in you do better homework then the interpretation that appears can vary - different. Parker added that if the context is conveyed by parents to their children then it is considered an order. It can also be considered annoying perlocution against the child if delivered every day. Whereas if the above speech is delivered by the student to his colleague who is a classmate and one boarding house then it is considered as a form of persuasion. The form of persuasion to complete the lecture duties before it is announced to be collected by the lecturer. If delivered by high school teachers (SMU) to their students then it can be regarded as a threat. In this case the student is required to complete the duties of the lecturer. In addition, such utterance is in fact an embarrassing form when presented in front of the class heard by all students.

\section{RESEARCH METHODS}

The source of this research data was the campaign media used by women legislative candidates during the campaign activity of legislative candidate 2014. The campaign period lasted for almost two months starting from January to February. The campaign media used in this research were billboards, banners, and stickers. The candidates' campaign media was taken from four areas namely Denpasar, Badung, Tabanan, and Gianyar.

Data collection methods used in this study was the referring method or "simak". Implementation of the method was supported by a number of data collection techniques. Recording technique was done by photographing media campaign media that were used as data. Furthermore, the sorting technique was done to sort the appropriate research data that was not appropriate. Certainly in this case, the data used by women legislative candidates was a priority as research data. After that the process of data collection followed by detailed reading techniques and recording techniques. Both techniques took place simultaneously meaning that while reading detailed languages in the media campaign then at that time recording was also done. The last technique to be implemented was a classification technique that aims to place the data - data based on the classification of speech acts and their meanings.

The method used during data analysis was descriptive qualitative method. Qualitative descriptive method apply description technique when conducted data analysis based on speech acts study and study of meaning. A qualified description technique would refer to theories concerning speech acts and the study of meaning. The influence of language on the media campaign candidates through acts of speech and interpretation was studied. Through the study of speech acts and discourse studies can be seen the tendency of speech acts from the media campaign outdoor space used by women legislative candidates. In addition, the study of discourse also makes it possible to look more deeply at the use of word, phrase, and sentence related to gender and politics.

\section{RESULT AND DISCUSSION}

Gender-related discussions include a study of the meaning of words or slogans used by legislative candidates on outdoor media campaigns and discourse studies on the overall meaning of the texts used. In this case, of course, related to the current condition in Indonesia.

Data 1 on the outdoor media campaign above contains gender data. The first thing that comes up is a visual model consisting of a female legislative candidate. The slogan that appears in data 1 is Now is Women's Opportunity Fought for the People's Interest.

In general, the meaning used in the slogan of data 1 is conceptual. In this case, all words used have real meaning and refer to actions, goods, people, and others [3]. Meaningfulness can be seen from the important words used in the above slogan such as opportunities, women, struggling, interests, and the people. The five words above are words that refer to specific references such as people and actions. Words such as women and people refer to people's references, while struggling tends to action. Meanwhile opportunities and interests refer to a certain form of things done by someone.

Meanings of gender arise from the use of the word woman. With the current emphasis on women's opportunities struggling to point to a very strong gendered subjectivity. The most basic meaning of course is related to the not optimal of women's struggle during this time in Indonesia. This happen although it has been proven by the existence of several female leaders as leaders in the era of colonial resistance. The current condition is the concern of the candidate by emphasizing the present slogan of women's fighting opportunities and for the benefit of the people.

The words for the people's interest have a great and wide meaning of importance for the whole sphere of society. Of course this if interpreted simply in interpreting the word woman then that appears is their role as housewives. Traditional roles that have always been attached to women are at home, parenting, cooking, and preparing everything related to the household. Meaning of course be different if associated with modern condition at this time. Where it appears the tendency of women more instrumental in providing income or help financially households that are felt 
not sufficient. If interpreted as a whole now the opportunity for women to fight for the benefit of the people has a meaning that today is an opportunity for women to do something or contribute to society.

A gender perspective also exists in data 2. Visually it can be seen if the outdoor campaign media is a campaign media of a female legislative candidate. So the gender perspective is also listed on the coming slogan to win with women surely can.

The meaning of the whole slogan used refers to the conceptual meaning. Both sentences on the slogan come to win and with women can certainly be interpreted as meaning that refers to people, actions, things, or other. In the first fragment comes to win a reference as an action related to competition or competition for the position as candidate for the people's representatives. Cards coming to win can also be interpreted as a form of confidence of the candidate to compete with other candidates as candidates for the people's representatives.

While with women it can be more indicative of the gender perspective that emphasizes the role of women. In this case, as a woman the candidate assumes if she is a representative of the women. So that togetherness with other women will be able or able to do something. Doing what is meant is of course the victory achieved in the elections to elect the people's representatives or legislative candidates. Viewed from a gender perspective, with women's fragments can certainly show that women's gender has a chance to win the competition or have equal opportunity with men. The gender perspective that has been associated with the position of women as the weak or the defeated does not appear in the data slogan 2. The more emphasized by the candidate is the power that enables women to be able to position themselves in victory or at least equal with men.

A gender perspective that is more emphasis on equality is seen in data 3. Equality appears in the slogan used by the legislative candidate on outdoor media campaigns. Data 3 shows visually the picture of female candidates from one political party. In his outdoor media campaign, the legislature wrote a slogan with men fighting for women's rights and gender equality.

Conceptual meaning is the meaning used in the slogan of outdoor campaign media on data 3 . In this case, the conceptual meaning that emerges is the meaning - the real meaning. True meanings such as men, struggle, women's rights, and gender equality. The use of the word male and female is the physical form that exists in the world. Verbs fight for referring to actions relating to something to be achieved. Gender equality is a concept of understanding about the differentiation of men and women socially and their functions in society.

Understanding the overall text that appears on outdoor media campaigns in data 3 , then obtained the simplest understanding of gender equality. The issue of equality or equality between men and women is the main thing used by the candidate. During this time, gender equality between men and women in Indonesia is still lame. Male dominance is a cultural product that shows a form of dominance that refers to the patrilineal culture shared by most cultures in Indonesia. It is also the concern of the candidate by providing additional information with the men. This information indicates an understanding of the condition of men and women in Indonesia. So to be able to achieve equality, then used the slogan with men to be able to fight for women's rights and gender equality.

The slogan on data 3 also shows the existence of a form of intergroup compromise. This form of compromise refers to the slogan with men. The slogan shows the existence of a form of cooperation or compromise that is linked between male and female gender. In this case, the emphasis raised by the candidate is not solely on women's gender alone. However, what is also a concern is the other gender of men and the emergence of a form of fighting for women's rights and gender equality. Here it can be noted that the emerging meaning is a form of gender-based compromise to fight for or promote gender equality and women's rights. Surely what has been common in people's understanding, women's rights and equality still cannot be interpreted as a form of equality.

The dominant meaning emerging in political discourse is conceptual meaning. Conceptual meaning is the meaning of reality. The significance of reality relates to actual conditions or actual and general realities. The meaning of reality that appears in the verbal slogan in the media of outdoor campaign of legislative candidates is the word of women, youth, men, and the interests of the people. While the choice of other words that are still meaningful conceptual is struggling, fighting, gender equality, and rise. The use of conceptual meaning in political discourse is certainly related to the understanding of potential voters. The conceptual meaning ensures the understanding of meaning among potential voters is the same. This is certainly to avoid the interpretation of each - different interpretation of each person.

In general, gender equality is the most prevalent political issue among women. Gender is the main thing other than the problems of other nations. The main point of gender becomes an issue that is conveyed by the legislative candidates considering the condition of women in Indonesia is still not equal with men. There are still differences and inequalities between men and women. This is related to a patrilineal culture that is more favorable to men who are hereditary in Indonesia. So in some slogans that become emphasis is the word woman. While the companion or third party that emerged, among others, men, youth, people, and others. However, the overall gender perspective focuses more on positioning women better in terms of politics as the candidates expect. 
Journal of A Sustainable Global South, p-ISSN: 2579-6062

\section{AcKNowledgements}

The researcher would like to thank all the parties who have been assisting the research implementation of the proposal submission process until the completion of the final research report. We would like to thank the Rector of Udayana University, Dean of Faculty of Arts Udayana University, and Chairman of the Institute for Research and Community Service

\section{REFERENCES}

[1] Dwi Narwoko, J. dan Suyanto, Bagong. 2013. "Sosiologi Teks Pengantar Dan Terapan". Jakarta : Kencana.

[2] Abdul rozak, dkk. 2013. "Pancasila, Demokrasi, Ham, dan Masyarakat Madani". Jakarta : Prenadamedia Group.

[3] Leech, Geoffrey. 1983. "Principle of Pragmatics". New York: Longman.

[4] Parker, Frank. 1986. "Linguistics for Non-Linguist. London". Taylor and Francis Ltd. 